\title{
Fragility fractures: the future epidemic and its challenges
}

\author{
Heike Bischoff-Ferrari
}

Received: 4 November 2012 / Accepted: 4 November 2012 /Published online: 28 November 2012

(C) ISS 2012

Fragility fractures contribute significantly to the morbidity and mortality of older individuals, and in a growing segment of the senior population a marked increase in these fractures is expected in the next 20 years $[1,2]$. The most rapidly growing segment of the senior population consists of men and women aged 85 years and older [2]. This translates in a rising number of all fragility fractures, especially those of the hip.

Hip fractures are the most serious and most frequent fractures occurring among seniors aged 75 years and older [3, 4], and an estimated 1 in 3 women, and 1 in 6 men will have sustained a hip fracture by their 90th decade [5]. Muscle weakness [6] and falling [7] are closely related to fragility fractures, and are critical in understanding them. Both muscle weakness and falling have been linked to the broad prevalence of vitamin D deficiency among the senior population.

Severe vitamin D deficiency (serum concentrations < $10 \mathrm{ng} / \mathrm{ml}$ or $<25 \mathrm{nmol} / 125$-hydroxyvitamin D) in the senior population causes secondary hyperparathyroidism, osteoporosis, and osteomalacia [8]. Histological osteomalacia, characterized by the accumulation of unmineralized matrix or osteoid in the skeleton, has been found to be common in several hip fracture case studies (12-44\%) [9-14]. At the same time it is well recognized that severe vitamin D deficiency is prevalent in about $60 \%$ of hip fracture patients $[15,16]$ and that vitamin $\mathrm{D}$ supplementation reduces the risk

H. Bischoff-Ferrari $(\square)$

Centre on Aging and Mobility, University of Zurich and City

Hospital Waid, Gloriastrasse 25,

8091 Zurich, Switzerland

e-mail: Heike.Bischoff@usz.ch

H. Bischoff-Ferrari

Department of Rheumatology, University Hospital Zurich,

Gloriastrasse 25,

8091 Zurich, Switzerland of hip fracture by $30 \%$ [17]. Thus, it is conceivable that a significant number of hip fractures occurring in seniors are explained by osteomalacic changes that soften the bone. Additionally, as a primary clinical sign of osteomalacia, muscle weakness may contribute to the risk of fracture [18], and vitamin D supplementation may not only mineralize bone, but has been shown to reduce the risk of falling by up to $34 \%[19,20]$.

Apart from hip fractures, the two other most common fragility fractures at non-vertebral sites are distal forearm and proximal humerus fractures, and, similar to hip fractures, distal forearm and proximal humerus fractures show a steep increase with age [3]. Notably, the circumstances of these fractures are strikingly different. Hip fractures tend to occur in less active individuals falling indoors from a standing height with little forward momentum, and they tend to fall sideways or straight down on their hip [21-23]. However, distal forearm or humerus fractures tend to occur among more active older individuals who are, correspondingly, more likely to be outdoors and have a greater forward momentum when they fall [24-26]. This may also explain why hip fracture incidence shows little to no seasonal change, while the winter/summer seasonal swing is pronounced in distal forearm and humerus fractures, and more so in men than in women [27]. Men aged 65 years and older are at a $51 \%$ greater risk of sustaining a distal forearm fracture and a $23 \%$ greater risk of sustaining a proximal humerus fracture in the winter compared with during the summer [27]. Women aged 65 years and older are at a $15 \%$ greater risk of sustaining a distal forearm fracture and a $19 \%$ greater risk of sustaining a proximal humerus fracture in the winter compared with during the summer [27]. In the same study, in winter, total snowfall was associated with a reduced risk of hip fracture ( $-5 \%$ per 20 inch), but an increased risk of distal forearm and proximal humerus fractures (6-12\%; $p<0.05$ at all sites) [27]. 
Compared with the three most common fragility fractures at non-vertebral sites (hip, distal forearm, and proximal humerus) the epidemiology of vertebral fractures is challenging with less than $30 \%$ of vertebral fractures coming to clinical attention [4]. Similar to the three nonvertebral fragility fractures, vertebral fractures increase exponentially after the age of 65 years among men and women, and incidence rates for vertebral fractures project between hip and radius fractures for both genders after the age of 75 years [4]. Women with a first vertebral fracture, are at more than a $19 \%$ risk of developing a second vertebral fracture during the following year [28], a 2.5-fold increased risk for any subsequent fracture [29], and a 2.8 -fold increased mortality rate within the following 10 years [30].

Notably, in men older than 80 years, vertebral fracture rates have been reported to be similar to those in women [31]. However, mechanistically there are gender-specific differences: more than $90 \%$ of vertebral fractures in women result from mild-to-moderate trauma, while, among men, this proportion is only $55 \%$ [32]. Severe vertebral deformities in both genders appear to have a predilection between $\mathrm{T} 10$ and $\mathrm{L} 1$ [32].

For a future perspective on the fragility fracture epidemic, it is important to note that fragility fractures are often followed by a second fragility fracture, and drawing attention to that first fracture and the need for secondary prevention is key in fragility fracture care. Based on a 16-year follow-up of one large population-based study in Australia [29], the absolute risk of a repeat fracture increases steeply and equally in men and women with age, despite a lower absolute risk of a first fracture among men. The relative risk of a repeat fracture among women aged 60-69, 70-79, and $80+$ years is 1.65 (95 \% CI: 1.18-2.32), 2.36 (1.91-2.92), and $1.80(1.45-2.25)$ respectively. The relative risk of a repeat fracture among men aged 60-69, 70-79, and 80+ years is 3.75 (2.19-6.43), $4.32(3.00-6.21)$, and 2.77 (1.69-4.54) respectively.

In summary, we will see many more fragility fractures in the coming 20 years and an interdisciplinary approach, including radiology, will be needed to face this challenge and prevent both first and repeat fragility fractures. From a radiology perspective, future approaches may include screening for signs of osteomalacia and the prevalence of vertebral fractures in any musculoskeletal radiology performed. Alternatively, new technologies for bone quality assessment, such as Xtreme computer tomography (CT) measurement, must find its way into clinical practice, and we extend the common use of dual-energy x-ray absorptiometry (DEXA) measurements to include vertebral morphometry and, depending on the further development of this technology, screening for signs of osteomalacia.

\section{References}

1. Gullberg B, Johnell O, Kanis JA. World-wide projections for hip fracture. Osteoporos Int. 1997;7(5):407-13.

2. Eberstadt N, Groth H. Europe's coming demographic challenge: unlocking the value of health. Washington, D.C.: American Enterprise Institute for Public Policy Research; 2007.

3. Barrett JA, Baron JA, Karagas MR, Beach ML. Fracture risk in the U.S. Medicare population. J Clin Epidemiol. 1999;52(3):243-9.

4. Cooper C, Melton 3rd LJ. Epidemiology of osteoporosis. Trends Endokrin Metab. 1992;314:224-9.

5. Birge SJ, Morrow-Howell N, Proctor EK. Hip fracture. Clin Geriatr Med. 1994;10(4):589-609.

6. Cummings SR, Nevitt MC, Browner WS, et al. Risk factors for hip fracture in white women. Study of Osteoporotic Fractures Research Group. N Engl J Med. 1995;332(12):767-73.

7. Centers for Disease Control and Prevention (CDC). Fatalities and injuries from falls among older adults - United States, 1993-2003 and 2001-2005. MMWR Morb Mortal Wkly Rep. 2006;55 (45):1221-4.

8. Holick MF. Vitamin D, deficiency. N Engl J Med. 2007;357 (3):266-81.

9. Harma M, Parviainen M, Koskinen T, et al. Bone density, histomorphometry and biochemistry in patients with fractures of the hip or spine. Ann Clin Res. 1987;19(6):378-82.

10. Bhan A, Rao AD, Rao DS. Osteomalacia as a result of vitamin D deficiency. Endocrinol Metab Clin N Am. 2012;39(2):321-31, viii-ix.

11. Aaron JE, Gallagher JC, Nordin BE. Seasonal variation of histological osteomalacia in femoral-neck fractures. Lancet. 1974;2 (7872):84-5.

12. Arnala I, Kyrola K, Kroger H, Alhava EM. Analysis of 245 consecutive hip fracture patients with special reference to bone metabolism. Ann Chir Gynaecol. 1997;86(4):343-7.

13. Wilton TJ, Hosking DJ, Pawley E, et al. Osteomalacia and femoral neck fractures in the elderly patient. J Bone Joint Surg Br. 1987;69 (3):388-90

14. Wilton TJ, Hosking DJ, Pawley E, et al. Screening for osteomalacia in elderly patients with femoral neck fractures. J Bone Joint Surg Br. 1987;69(5):765-8.

15. LeBoff MS, Kohlmeier L, Hurwitz S, et al. Occult vitamin D deficiency in postmenopausal US women with acute hip fracture. JAMA. 1999;281(16):1505-11.

16. Bischoff-Ferrari HA, Can U, Staehelin HB, et al. Severe vitamin D deficiency in Swiss hip fracture patients. Bone. 2008;42(3):597602.

17. Bischoff-Ferrari HA, Orav EJ, Willett WC, et al. A pooled analysis of vitamin $\mathrm{D}$ dose requirements for fracture prevention. $\mathrm{N}$ Engl $\mathrm{J}$ Med. 38(1):81-91, viii-ix.

18. Schott GD, Wills MR. Muscle weakness in osteomalacia. Lancet. 1976;1(7960):626-9.

19. Bischoff-Ferrari HA, Willett WC, Orav EJ, et al. Re: fall prevention with vitamin D. Clarifications needed. http://wwwbmjcom/ content/339/bmjb3692?tab=responses Accessed 13 February 2012.

20. Bischoff-Ferrari HA, Dawson-Hughes B, Staehelin HB, et al. Fall prevention with supplemental and active forms of vitamin D: a meta-analysis of randomised controlled trials. BMJ. 2009;339(1): b3692.

21. Nevitt MC, Cummings SR. Type of fall and risk of hip and wrist fractures: the study of osteoporotic fractures. J Am Geriatr Soc. 1994;42(8):909.

22. Carter SE, Campbell EM, Sanson-Fisher RW, Gillespie WJ. Accidents in older people living at home: a community-based 
study assessing prevalence, type, location and injuries. Aust N Z J Public Health. 2000;24(6):633-6.

23. Campbell AJ, Borrie MJ, Spears GF, et al. Circumstances and consequences of falls experienced by a community population 70 years and over during a prospective study. Age Ageing. 1990;19(2):136-41.

24. O'Neill TW, Marsden D, Adams JE, Silman AJ. Risk factors, falls, and fracture of the distal forearm in Manchester, UK. J Epidemiol Community Health. 1996;50(3):288-92.

25. Graafmans WC, Ooms ME, Bezemer PD, et al. Different risk profiles for hip fractures and distal forearm fractures: a prospective study. Osteoporos Int. 1996;6(6):427-31.

26. Keegan TH, Kelsey JL, King AC, et al. Characteristics of fallers who fracture at the foot, distal forearm, proximal humerus, pelvis, and shaft of the tibia/fibula compared with fallers who do not fracture. Am J Epidemiol. 2004;159(2):192-203.
27. Bischoff-Ferrari HA, Orav JE, Barrett JA, Baron JA. Effect of seasonality and weather on fracture risk in individuals 65 years and older. Osteoporos Int. 2007;18(9):1225-33.

28. Lindsay R, Silverman SL, Cooper C, et al. Risk of new vertebral fracture in the year following a fracture. JAMA. 2001;285(3):320-3.

29. Center JR, Bliuc D, Nguyen TV, Eisman JA. Risk of subsequent fracture after low-trauma fracture in men and women. JAMA. 2007;297(4):387-94.

30. Hasserius R, Karlsson MK, Jonsson B, et al. Long-term morbidity and mortality after a clinically diagnosed vertebral fracture in the elderly - a 12- and 22-year follow-up of 257 patients. Calcif Tissue Int. 2005;76(4):235-42.

31. Praemer A, Furner S, Rice DP. Musculoskeletal conditions in the United States. Rosemont, IL. Am Acad Orthop Surg. 1992:145-70.

32. Melton 3rd LJ, Lane AW, Cooper C, et al. Prevalence and incidence of vertebral deformities. Osteoporos Int. 1993;3(3):113-9. 